\title{
Polyethylene loss of ductility during oxidation: Effect of initial molar mass distribution
}

\author{
Armando F. Reano, Alain Guinault, Emmanuel Richaud*, Bruno Fayolle \\ Laboratoire PIMM, Ensam, CNRS, Cnam, 151 Boulevard de l'Hôpital, 75013 Paris, France
}

\section{A R T I C L E I N F O}

\section{Keywords:}

Polyethylene

Oxidation

Loss of ductility

Polydispersity

Chemicrystallization

\begin{abstract}
A B S T R A C T
This paper reports a study of thermal oxidation induced embrittlement in several polyethylene grades differing mainly by the broadness of the molar mass distribution (ranging for lower than 3 to more than 30). Thermal oxidation was monitored at macromolecular scale (Gel Permeation Chromatography, Differential Scanning Calorimetry) and macroscopic scale (tensile tests). As expected, the samples undergo predominant chain scission and plastic deformation is suppressed below a critical molar mass value $\left(\mathrm{M}_{\mathrm{C}}{ }_{\mathrm{C}}\right)$. Even though this latter was previously reported to be independent of the initial weight average molar mass, it is shown here that it depends on initial polydispersity index. Samples were also shown to undergo chemicrystallization, i.e. that segments released by chain scissions migrate into the crystalline phase with a yield increasing with initial polydispersity index. Finally, the main novelty of this work is to evidence that the previously proposed end-of-life criteria at macromolecular level linked to loss of ductility (critical molar mass, crystallization yield) depend on the initial polydispersity index.
\end{abstract}

\section{Introduction}

Polyethylene (PE) mechanical, thermal and rheological properties allow it to be used in a large range of application areas (packaging, automotive ...). Organometallic catalysts were developed to produce PE with well-defined structures (average molecular mass, crystallization degree, etc ...) [1,2]. Oxidation mechanisms [3], kinetics [4] and the subsequent loss of ductility, often so called embrittlement (even if this term is rather linked to the loss of toughness instead of ultimate elongation) [5] are well documented in literature together with the detrimental role of metallic polymerization catalysts on oxidative stability [6].

Polymers with excellent mechanical properties are needed to overcome environmental stresses. In order to reach higher mechanical properties for specific applications, PE with high molecular weight had been commercialized $[7,8]$. The main drawback of high molecular weight PE's is their high melt viscosity which limits their processability. Some novel polymerization technologies have been developed to produce bimodal grades of polyethylene, i.e. made of two major chain length populations leading thus to a higher polydispersity index. The presence of high molecular weight chain induces improved mechanical properties and low molecular weight fraction makes process easier.

To the best of our knowledge, there is no information in literature about the degradation of bimodal PE's, about the effect of polydispersity on the oxidation induced loss of ductility and about the possible consequences of the presence of the two chain length populations on the end-of-life criteria. In these previous studies [5,9], it has been proposed that plastic deformation is suppressed when the weight average molar becomes lower a critical value, the critical molar mass $\left(\mathrm{M}_{\mathrm{C}}{ }_{\mathrm{C}}\right)$ whatever the initial molar mass value $\left(\mathrm{M}_{\mathrm{Wo}}\right)$. For the $\mathrm{PE}$ family, it has been witnessed that the $\mathrm{M}_{\mathrm{C}}{ }_{\mathrm{C}}$ value associated to the ductile-brittle transition is spread over the $40-100 \mathrm{~kg} \mathrm{~mol}^{-1}$ molar mass interval. However, in this approach, the influence of initial value for the polydispersity index $\left(\mathrm{PDI}_{0}\right)$ and/or the initial molar mass value $\mathrm{M}_{\mathrm{Wo}}$ on $\mathrm{M}_{\mathrm{C}}{ }_{\mathrm{C}}$ has not been taken into account.

The aim of this paper is hence to study the homogeneous thermal oxidation of lowly and highly polydispersed PE's and to focus on the macromolecular and mechanical changes. For that purpose, five PE grades were selected based on supplier data sheet, with a MFI value acceptable for extrusion and varying polydispersity index (assuming that high dispersity leads to high weight average molecular weight).

\section{Materials and methods}

\subsection{Materials}

The samples are listed in Table 1 with their designation, initial macromolecular and mechanical properties (measured as detailed in

\footnotetext{
* Corresponding author.

E-mail address: emmanuel.richaud@ensam.eu (E. Richaud).
} 
Table 1

Sample designation and initials macromolecular and mechanical properties experimentally determined.

\begin{tabular}{|c|c|c|c|c|c|c|c|c|c|}
\hline Sample Name & $\begin{array}{l}\text { Nature of } \\
\text { catalyst }^{\mathrm{a}}\end{array}$ & $\mathrm{PDI}_{0}$ & $\begin{array}{l}\mathrm{M}_{\mathrm{n} 0}(\mathrm{GPC}) \\
\left(\mathrm{kg} \mathrm{mol}^{-1}\right)\end{array}$ & $\begin{array}{l}\mathrm{M}_{\mathrm{wo}}(\mathrm{GPC}) \\
\left(\mathrm{kg} \mathrm{mol}^{-1}\right)\end{array}$ & $\begin{array}{l}\mathrm{M}_{\mathrm{wo}} \text { (rheo.) } \\
\left(\mathrm{kg} \mathrm{mol}^{-1}\right)\end{array}$ & $\varepsilon_{\mathrm{R} 0}(\%)$ & $\chi c_{0}(\%)$ & $\begin{array}{l}\text { Vinyl index } \\
\left(\mathrm{A}_{910} / \mathrm{A}_{2017}\right)\end{array}$ & $\begin{array}{l}\text { Branching index } \\
\left(\mathrm{A}_{1360} / \mathrm{A}_{1450}\right)\end{array}$ \\
\hline $\mathrm{PE}_{2.9}$ & $\mathrm{~m}$ & 2.9 & 27.0 & 81.0 & 75.6 & $909 \pm 182$ & 53.0 & 0.08 & 3.20 \\
\hline $\mathrm{PE}_{3.4}$ & $\mathrm{~m}$ & 3.4 & 39.0 & 133.0 & 130.4 & $869 \pm 25$ & 65.7 & 0.07 & 4.91 \\
\hline $\mathrm{PE}_{5.1}$ & $\mathrm{~m}$ & 5.1 & 29.5 & 149.0 & 158.0 & $682.8 \pm 13$ & 43.5 & 0.05 & 2.13 \\
\hline $\mathrm{PE}_{14.5}$ & $\mathrm{ZN}$ & 14.5 & 16.0 & 283.0 & 249.1 & $488.2 \pm 10$ & 56.6 & 0.23 & 3.99 \\
\hline $\mathrm{PE}_{33.0}$ & Phillipps & 33.0 & 14.0 & 463.5 & 321.5 & $526.0 \pm 41$ & 47.8 & 1.93 & 2.69 \\
\hline
\end{tabular}

${ }^{\mathrm{a}} \mathrm{m}=$ metallocene catalyst; ZN = Ziegler-Natta catalyst; Phillipps = Phillipps catalyst.

the following). The five PE grades investigated here differ by nature of polymerization catalysts, initials number and weight average molar mass $\left(\mathrm{M}_{\mathrm{n} 0}, \mathrm{M}_{\mathrm{w} 0}\right)$, initial polydispersity index $\left(\mathrm{PDI}_{0}\right)$ and crystallinity ratio (Table 1). MWD measurements were performed by GPC during the oxidation process. Some rheological experiments were also performed to measure the Newtonian viscosity in molten state $\left(200^{\circ} \mathrm{C}\right)$ to confirm $\mathrm{M}_{\mathrm{Wo}}$ values. As it is shown in Table 1, a good correlation was witnessed between the $\mathrm{M}_{\mathrm{wo}}$ values obtained by GPC and ones obtained by the rheological way. Vinyl index were measured by FTIR from the $910 \mathrm{~cm}^{-1}$ absorbance. The presence of short chain branching was estimated from the ratio of absorbances at 1370 to $1450 \mathrm{~cm}^{-1}$ (NB: It was chosen to consider the whole area of the absorbance in a first approach since there are actually several maxima for the absorbance centered at $1370 \mathrm{~cm}^{-1}$ [10]).

Samples were studied as $15 \mu \mathrm{m}$ thick films in order to avoid the complications linked to the so called Diffusion Limited Oxidation $[11,12]$. Films were obtained by blown-film extrusion with a single screw extruder (25 mm diameter, 20D) at $30 \mathrm{rpm}$, under a temperature profile between 200 and $240{ }^{\circ} \mathrm{C}$, a $50 \mathrm{~mm}$ diameter blown die, 0.8 die gap and an air cooling device.

In order to focus only on the influence of microstructure on PE thermal oxidation and not on stabilizers initially introduced, films were purified by refluxing about $300 \mathrm{mg}$ of PE films in a dichloromethane (VWR reference 23354.326$)$ solution $(250 \mathrm{~mL}$ ) during $24 \mathrm{~h}$. The total extraction of stabilizer was checked from the disappearance of Oxygen Induction Time value measured at $200^{\circ} \mathrm{C}$.

\subsection{Exposure conditions}

Films were aged at $100{ }^{\circ} \mathrm{C}$ in ventilated ovens (SCS), this temperature being chosen as a compromise between a high oxidation rate and an oxidation in a solid state i.e. below the onset of the melting peak.

\subsection{Characterization}

\subsubsection{Gel permeation chromatography (GPC)}

GPC analyses were performed using an Agilent HT 220 system equipped with a refractive index (RI) detector in 1,2,4-trichlorobenzene (TCB) stabilized with $0.0125 \%$ BHT at $135^{\circ} \mathrm{C}$ as mobile phase with two PLgel Olexis columns (Agilent Technology) as stationary phase. PE films were dissolved in TCB (about $3 \mathrm{~g} \mathrm{~L}^{-1}$ ). The elution method consisted in an isocratic step at $1 \mathrm{~mL} \mathrm{~min}^{-1}$ flow of TCB for $30 \mathrm{~min}$ at $135^{\circ} \mathrm{C}$. The calibration was done with polystyrene (PS) standards. Molar masses were then estimated using the universal calibration with $\mathrm{K}=12,1 \times 10^{5} \mathrm{dg} \mathrm{L}^{-1}$ and $\alpha=0,707$ for PS, and $\mathrm{K}=40,6 \times 10^{5}$ and $\alpha=0,725$ for PE [13].

GPC chromatograms shown in Fig. 1 for the polymers before exposure allow for the number and weight average molecular weight $\left(M_{n}\right.$ and $\mathrm{M}_{\mathrm{w}}$ ) and polydispersity index (PDI) assessment. Samples PDI range from 2.7 to 33.0. As expected, the narrower distributions (or lowest $\mathrm{PDI}_{0}$ ) correspond to materials made from metallocene catalysts [14].

\subsubsection{Differential scanning calorimetry (DSC)}

Analyses were performed using a Q1000 (TA Instruments)

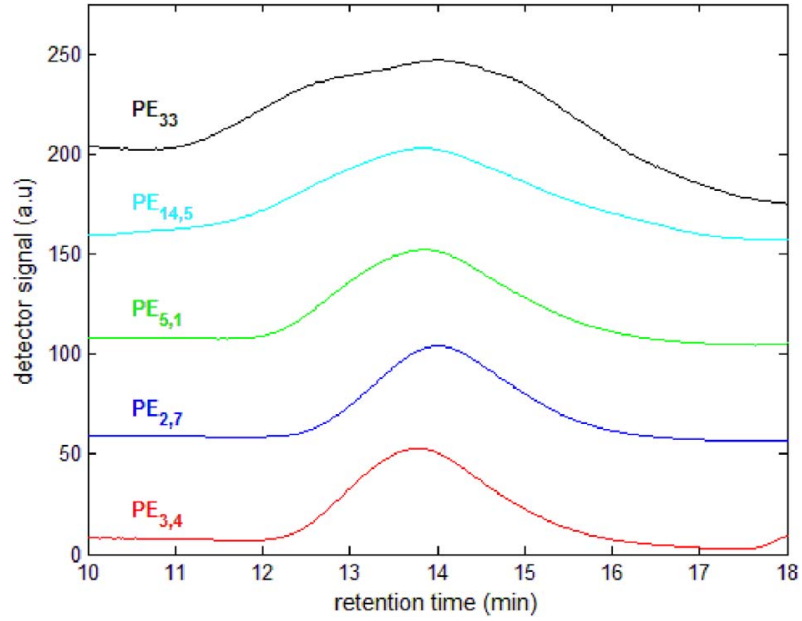

Fig. 1. GPC chromatograms of initial PE samples.

calibrated with indium standard. About $5 \mathrm{mg}$ samples sealed in standard aluminum pans were heated from -50 to $200{ }^{\circ} \mathrm{C}$ at a $10{ }^{\circ} \mathrm{C} \mathrm{min}{ }^{-1}$ ramp under $\mathrm{N}_{2}$ flow $\left(50 \mathrm{~mL} \mathrm{~min}^{-1}\right)$. The percent crystallinity was classical assessed from:

$x_{C}=\frac{\Delta H_{m}}{\Delta H_{m 100}}$

where $\Delta \mathrm{H}_{\mathrm{m}}$ and $\Delta \mathrm{H}_{\mathrm{m} 100}$ are respectively the melting enthalpy of the investigated sample and the melting enthalpy for an ideally $100 \%$ crystalline PE sample, which is equal to $288 \mathrm{~J} \mathrm{~g}^{-1}$ [15].

\subsubsection{Tensile tests}

Tensile tests were carried out at room temperature on Instron ${ }^{\circ} 1301$ machine equipped with a $1 \mathrm{kN}$ cell load; the cross-head speed was $1 \mathrm{~mm} \mathrm{~min}^{-1}$ on samples with dimensions according to standard ISO527-2 (1BB). As a result, nominal strain rate was $8.310^{-3} \mathrm{~s}^{-1}$. Only nominal strain at break values $\left(\varepsilon_{R}\right)$ was reported with varying ageing times since it was shown that strain at break is the most relevant parameter to monitor the residual ductility as a function of ageing duration for these highly ductile polymers [16]. At least 5 measurements were done for each sample.

\section{Results}

\subsection{Mechanical properties changes}

Fig. 2 displays the changes of strain at break of sample with exposure time. All samples exhibit a similar behavior: first an induction period followed by a sudden decrease of strain at break. The time to ultimate properties loss can be defined as the onset of strain at break decrease. Its duration is undoubtedly related to the content in residual double bonds, short chain branching, in link with the nature of metallic catalysts [6] and unstable groups generated from the processing stage [17]. However, this will not be discussed here in the sake of conciseness 


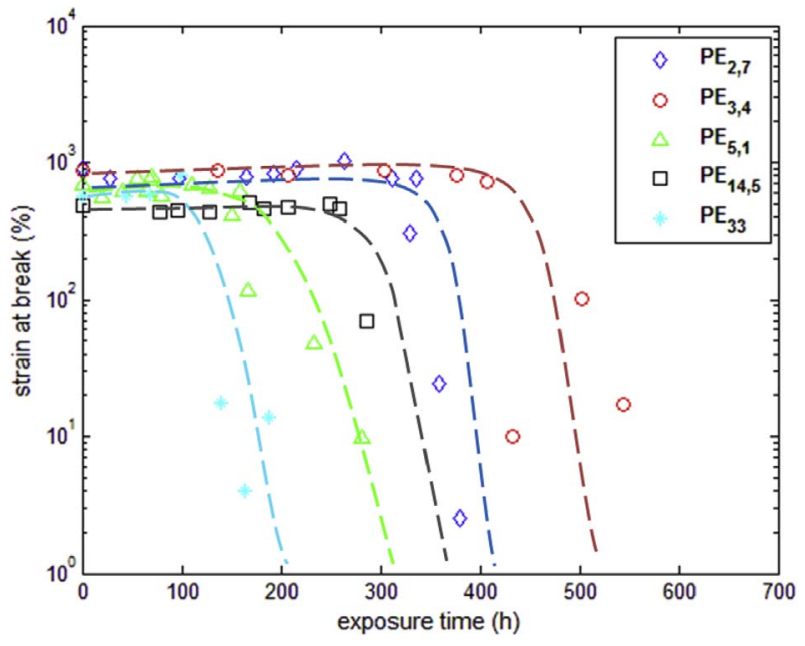

Fig. 2. Strain at break changes during thermal ageing at $100^{\circ} \mathrm{C}$.

since this paper rather focuses on the structure properties relationships involved in PE thermal oxidation (NB: moreover, the link between for example the presence of short branching and end-of-life criteria in terms of structure-properties relationships presented in this paper is for us unclear). It was also checked that the induction period durations (from the mechanical point of view) are consistent with those observed for carbonyl build up as monitored by FTIR spectroscopy.

\subsection{Molar mass changes}

By assuming that the depletion of strain at break originates from the decrease of molecular weight, it was previously established that when molar mass is decreased above a critical value, the polymer can be considered as "brittle" i.e. does not display any plastic deformation anymore [5]. In other words, a critical molar mass can be associated to ductile-brittle transition during the oxidation process. Fig. 3 shows the changes of the normalized average molecular weight $\mathrm{M}_{\mathrm{w}} / \mathrm{M}_{\mathrm{Wo}}$ as a function of the exposure time. It appears that, after an induction period, the molar mass drops indicating a predominant chain scission process for all samples. By comparing the Figs. 2 and 3, it is noteworthy that the molar mass drop is witnessed before the strain at break drop for a given polymer.

PDI changes were followed for all samples at different exposure times in Fig. 4. Two main behaviors can be easily observed:

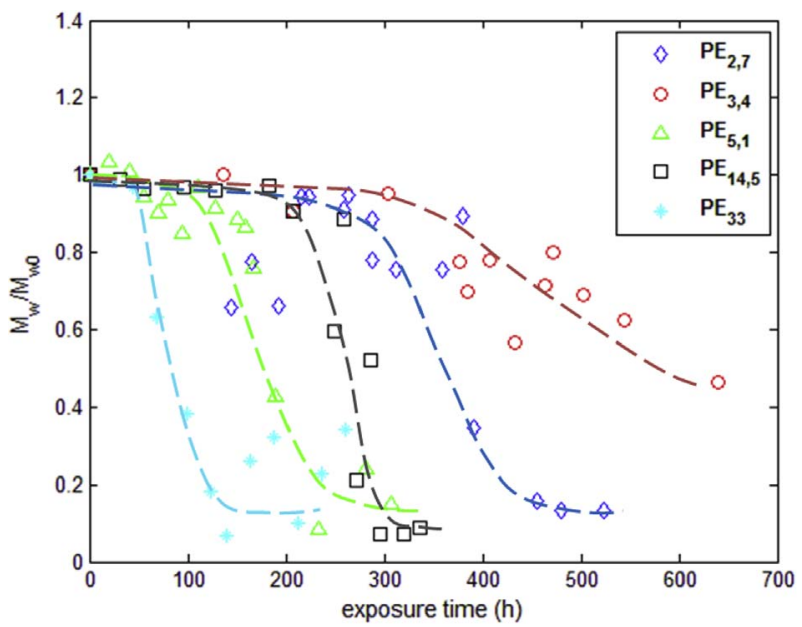

Fig. 3. Changes of normalized average weight molar mass during thermal ageing at $100^{\circ} \mathrm{C}$.
- On one hand, PDI values of highly dispersed samples $\left(\mathrm{PE}_{33,0}, \mathrm{PE}_{17,5}\right.$ and $\mathrm{PE}_{5,1}$ ) decrease [18] and reach a plateau value close to 5 .

- On the other hand, PDI values of low dispersed samples $\left(\mathrm{PE}_{2,7}\right.$, $\mathrm{PE}_{3,4}$ ) slightly increase, probably due to crosslinking (as it will be discussed later) and reach a plateau value close to 4 .

As a result, PDI tends towards an asymptotic value close to 5 whatever the PDI initial value as it will be discussed later.

The changes in number and weight average molar masses allow for an assessment chain scission ( $\mathrm{s}$ ) and crosslink ( $\mathrm{x}$ ) formation as follows [19]:

$\frac{1}{M_{n}}-\frac{1}{M_{n 0}}=s-x$

$\frac{1}{M_{w}}-\frac{1}{M_{w 0}}=\frac{s}{2}-2 x$

According to those equations, the concentrations in chain scissions and crosslinking can be easily determined. They are plotted in Fig. 5 . One can first notice that scissions are 5-6 times higher than crosslinks consistently with [5].

According to Eqs. (2) and (3):

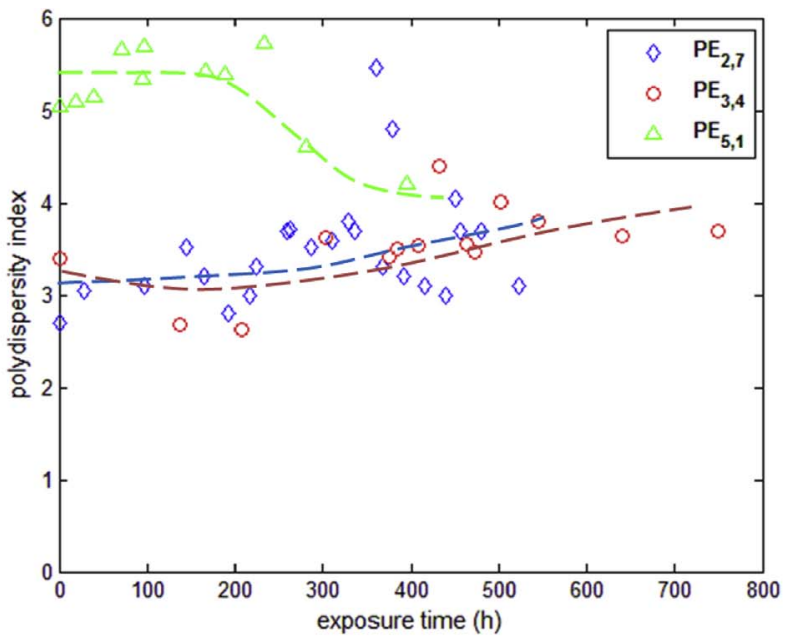

(a)

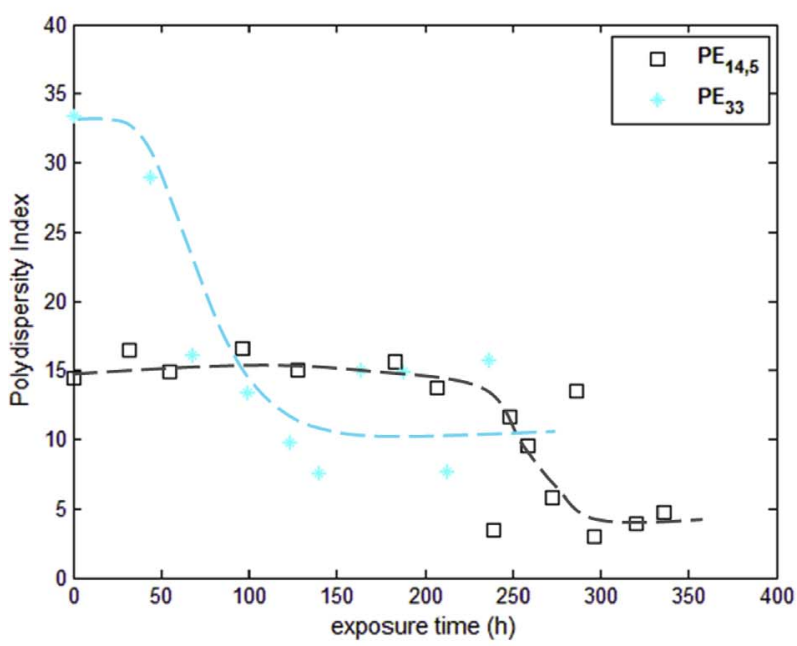

(b)

Fig. 4. Polydispersity index (PDI) changes during thermal ageing at $100{ }^{\circ} \mathrm{C}$ for $\mathrm{PE}_{2.7}$, $\mathrm{PE}_{3.4}, \mathrm{PE}_{5.7}$ (a) and $\mathrm{PE}_{17.5}$ and $\mathrm{PE}_{33}$ (b). 


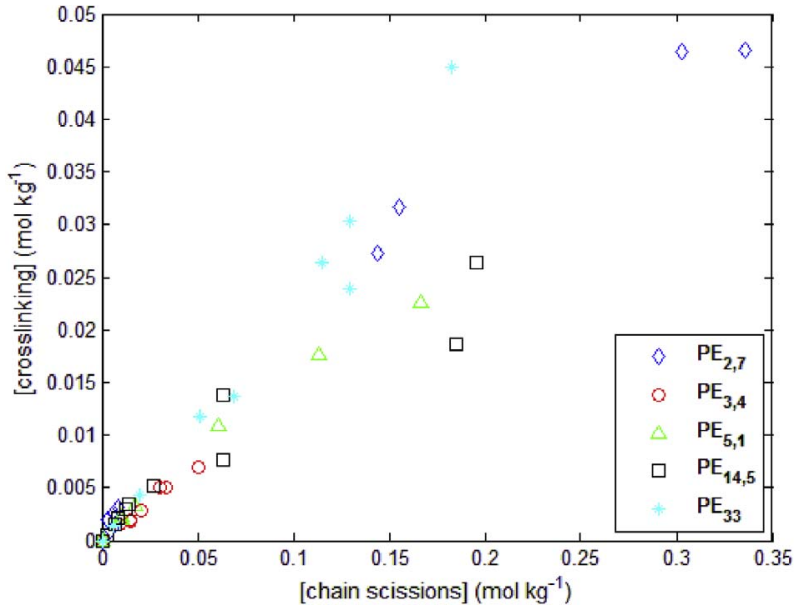

Fig. 5. Changes of number of crosslink as a function of chain scission number during thermal ageing at $100^{\circ} \mathrm{C}$.

$I P=\frac{I P_{0}+s \cdot M_{w 0}-x \cdot M_{w 0}}{1+\frac{s}{2} \cdot M_{w 0}-2 x \cdot M_{w 0}}$

Since s and $\mathrm{x}$ are proportional (Fig. 5), on sees that IP tends towards $4 \pm 1$ if $s / x=7 \pm 1$ at high conversion degree (i.e. consistently with the Fig. 4).

It appears also that $\mathrm{PE}_{33,0}$ seems to undergo more crosslink than other PE grades for a given chain scission number. The most probable explanation for us is its highest concentration in double bonds (Table 1), those latter being able to react with radicals generated by oxidation mechanism [20]. However, as recalled in Ref. [5], the concentration in crosslinks necessary to observe the loss of ductility (for example in radiochemically aged $\mathrm{PE}$ ) is much higher than observed in Fig. 5. As a result, we will consider that the mechanism of ductility loss is governed by the chain scission process even if initial PDI value can modify the macromolecular end-of-life criteria for the ductile-brittle transition.

\subsection{Crystallinity changes}

Some mechanical properties can also be related to changes in crystalline morphology. In Ref. [9], we have proposed that the embrittlement (oxidation induced loss of plastic deformation) can be associated to crystalline morphology changes: the chain scission lead to an increase of crystallinity by a lamellar thickening. This lamellar thickening then contributes to decrease the thickness of amorphous layer between crystalline lamellae governing the interlamellar connection. Knowing the ductile-brittle transition can be driven by the interlamellar connection, an increase of oxidation induced crystallinity, often called chemicrystallization, can thus lead to embrittle the semicrystalline polymers.

Crystalline morphology changes were here followed from the melting peak of aged samples, which allows the crystalline ratio to be estimated. As expected, DSC analyses show that percent crystallinity increases during thermal aging (Fig. 6) whereas the melting peak shape and melting point temperature do not significantly change (see Appendix).

\section{Discussion}

Despite all PE's under investigation seem to perish by a decrease of their molar mass induced by chain scissions, Fig. 4 suggests some differences between them. Knowing that the narrower molar mass distributions seem to broaden whereas the initially broad ones turn narrower, the main aim of this discussion is hence to comment the possible effects of polydispersity on the mechanisms responsible for the loss of

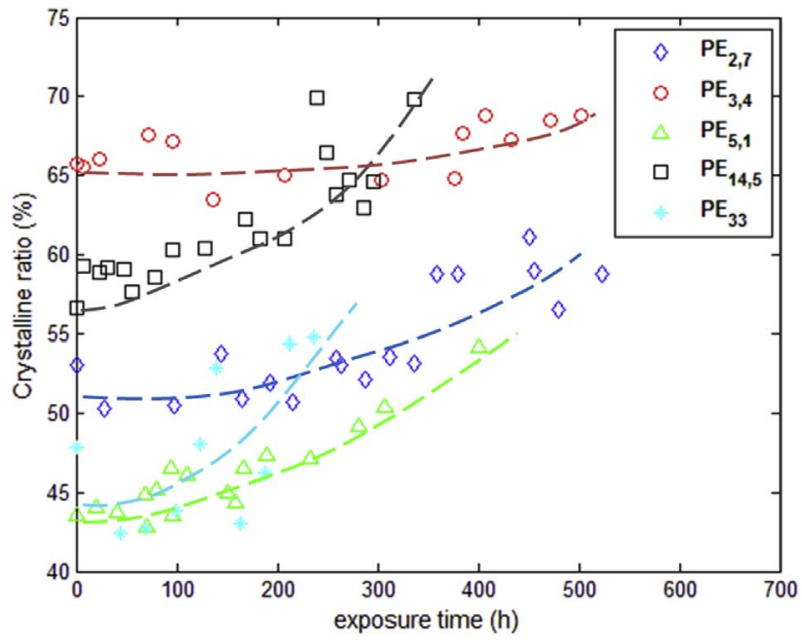

Fig. 6. Percent crystallinity changes during ageing at $100^{\circ} \mathrm{C}$ (estimated from Eq. (1)).

plastic deformation of PE by investigating:

- the existence of end-of-life criterion such as the "critical molar mass" value delimitating the ductile and the brittle domain.

- the mechanism of chemicrystallization also expected to be involved in the loss of ductility of semi-crystalline polymers with amorphous phase in rubbery state.

\subsection{On the effect of initial polydispersity on "critical molar mass" $\left(M_{C}^{\prime}\right)$}

As previously mentioned a decrease of molecular mass comes from chain scissions occurring during thermal oxidation and involves the loss of ultimate mechanical properties, leading to loss of ductility. Previous studies highlighted that a critical value of molecular mass $\left(\mathrm{M}_{\mathrm{C}}{ }_{\mathrm{C}}\right)$ is characteristic to the loss of ductility $[5,9,16]$. The compilation of strain at break - molar mass data from various authors (irrespectively of PE microstructure, aging history, processing conditions, strain rate, molecular weight ...) lead to that $\mathrm{M}_{\mathrm{C}}^{\prime}=70 \pm 30 \mathrm{~kg} \mathrm{~mol}^{-1}$ [9]. It was also assumed that this value depends in a first approach only on the nature of the polymer and that for semi-crystalline polymers with amorphous phase in rubbery state: $\mathrm{M}_{C}^{\prime}=50 . \mathrm{M}_{\mathrm{e}}, \mathrm{M}_{\mathrm{e}}$ being the average molar mass between entanglements [5] and equal to $1.4 \mathrm{~kg} \mathrm{~mol}^{-1}$ for polyethylene [21]. To check out this scenario, strain at break values were plotted as a function of $\mathrm{M}_{\mathrm{W}}$ in Fig. 7. The $\mathrm{M}_{\mathrm{C}}^{\prime}$ value $\left(70 \pm 30 \mathrm{~kg} \mathrm{~mol}^{-1}\right)$ is confirmed here in the case of the initial narrow molar mass distributions: for $\mathrm{PDI}_{0}=2-3.5, \mathrm{M}_{\mathrm{C}}^{\prime}=40-80 \mathrm{~kg} \mathrm{~mol}^{-1}$ (Fig. 7).

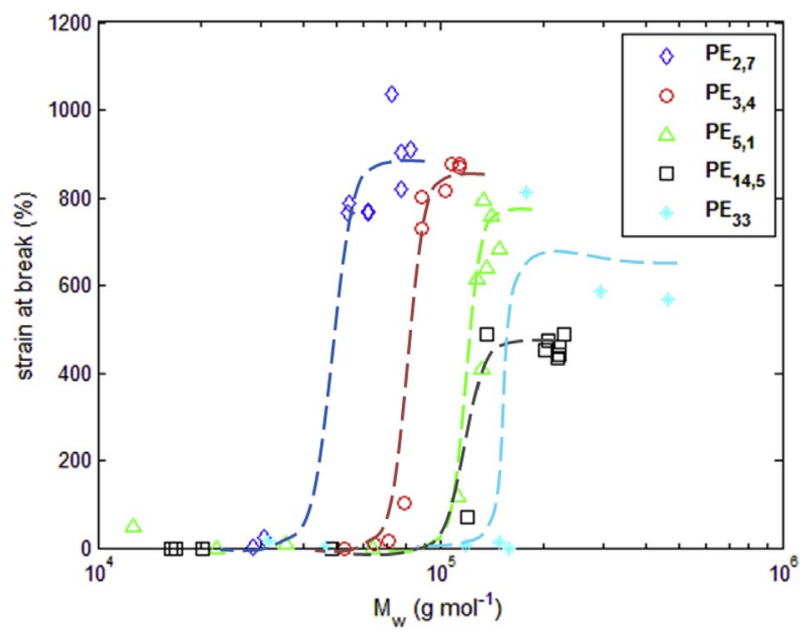

Fig. 7. Strain at break versus weight average molar mass during thermal ageing at $100^{\circ} \mathrm{C}$. 


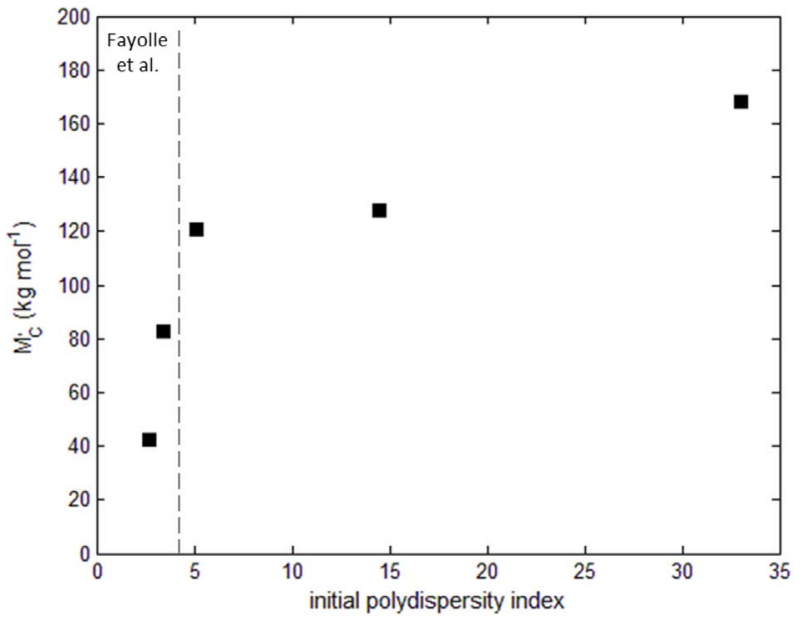

Fig. 8. $\mathrm{M}_{\mathrm{C}}$ value for PE grade with various initial polydispersity index.

However, it seems also clear that polymers characterized by the broadest molar mass distribution (PDI $>5$ ) display a higher critical value $\mathrm{M}_{\mathrm{C}}^{\prime}$ as confirmed in Fig. 8 where $\mathrm{M}_{\mathrm{C}}^{\prime}$ values are plotted as a function of the initial polydispersity index for samples under investigation. Contrarily to the proposal according to which $\mathrm{M}_{\mathrm{C}}{ }_{\mathrm{C}}$ is almost the same for a given polymer family [5], $\mathrm{M}_{\mathrm{C}}{ }_{\mathrm{C}}$ is shown to increase significantly with initial polydispersity index (from about 40 to $160 \mathrm{~kg} \mathrm{~mol}^{-1}$ ). In other words, the presence of very long chains favors the plasticity but this is compensated (at least in part) by a greater sensitivity to oxidation induced chain scissions. Let us recall that the probability that a chain undergoes a scission is equal to $M_{n 0} . s, M_{n 0}$ being the initial molar mass and $s$ the chain scission concentration, which means that longest chains are statistically much more sensitive to chain scissions than shortest ones. In the light of these results, polydispersity can be recognized as the main impacting factor on $\mathrm{M}_{\mathrm{c}}{ }_{\mathrm{c}}$ (NB: at least in the case of commercial PE's comparable to those presented in Table 1) meanwhile the (fictive) case of samples made of very dispersed population of very short chains being initially brittle will not considered here. It was thus chosen to study it effect on oxidation more in details.

\subsection{On the effect of initial polydispersity on chemicrystallization}

Chain scissions are responsible for increase in percent crystallinity: it is generally accepted that during ageing of a polymer having its amorphous phase is in the rubbery state, short segments generated by chain scissions can integrate into the crystalline phase. This chemicrystallization phenomenon [22] can be characterized by its yield (y) as defined below:

$y=\frac{1}{M_{m}} \cdot \frac{d x_{C}}{d s}$

Where $M_{m}$ is the molar mass of the repetitive unit. When monitoring crystallization degree during thermal ageing, one can clearly observe an increase (Fig. 6). The chemicrystallization yield can be calculated from Eq. (5). If the order of magnitude is well consistent with ones found in Ref. [23], it was observed in Fig. 9 that this value increases linearly with the initial polydispersity index. One can hence conclude that in polydispersed $\mathrm{PE}$, high molar masses population is mainly affected by oxidation, and the resulting chain segments would be more likely to undergo crystallization.

\subsection{On the effect of polydispersity index on end-of-life criteria}

Last, we were interested in the influence of crystalline morphology on the loss of ductility. It was proposed that semi-crystalline polymers

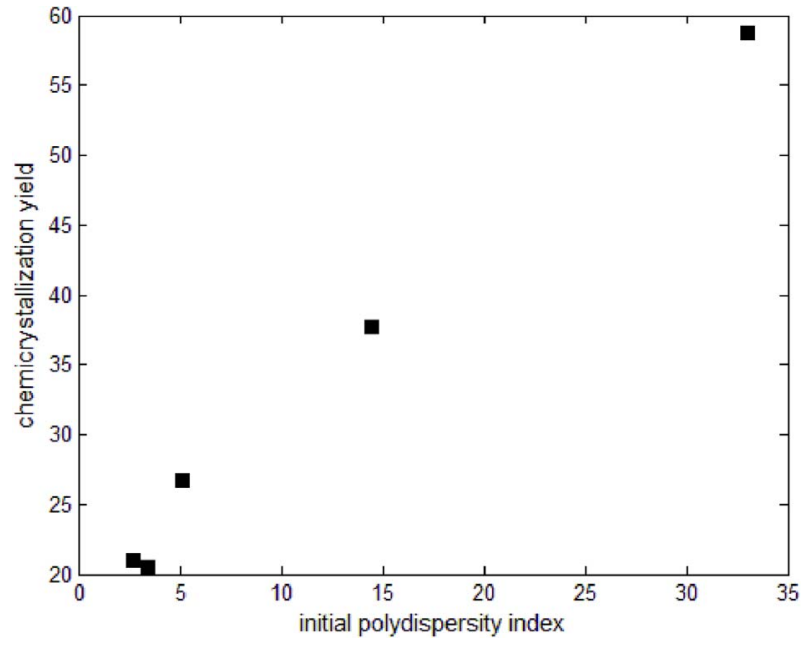

Fig. 9. Chemicrystallization yield versus initial polydispersity index.

don't show macroscopic plastic deformation when molar mass becomes lower than the critical molar mass $\mathrm{M}_{\mathrm{C}}$ but this value is influenced in part by the crystalline morphology. The decrease of thickness of interlamellae amorphous phase $\left(l_{a}\right)$ is indeed also involved in the loss of ductility and $l_{\mathrm{a}}$ has to be higher than a critical value to allow the development of plastic deformation in samples [9]. This leads to a mixed end-of-life criterion $\mathrm{M}_{\mathrm{C}}{ }_{\mathrm{C}}-\mathrm{l}_{\mathrm{aC}}$, which was illustrated for example in the case of polyamide 11 [24]. In the frame of the same approach, we have plotted the percent crystallinity vs the average molecular weight $\left(\mathrm{M}_{\mathrm{w}}\right)$ in Fig. 10 for all the ageing time (NB: the reason why we use crystalline ratio instead of thickness of interlamellar amorphous phase are explained in Appendix). This latter calls for the following comments:

- samples with molar mass higher than a critical value and crystalline ratio lower (or thickness of interlamellar amorphous phase higher than a critical value) are ductile.

- samples with molar mass lower than a critical value and crystalline ratio higher (or thickness of interlamellar amorphous phase lower than a critical value) don't show macroscopic plastic deformation.

According to Fig. 10, the boundary between the two domains would be shifted depending on the initial polydispersity index but this remains to be confirmed in forthcoming study.

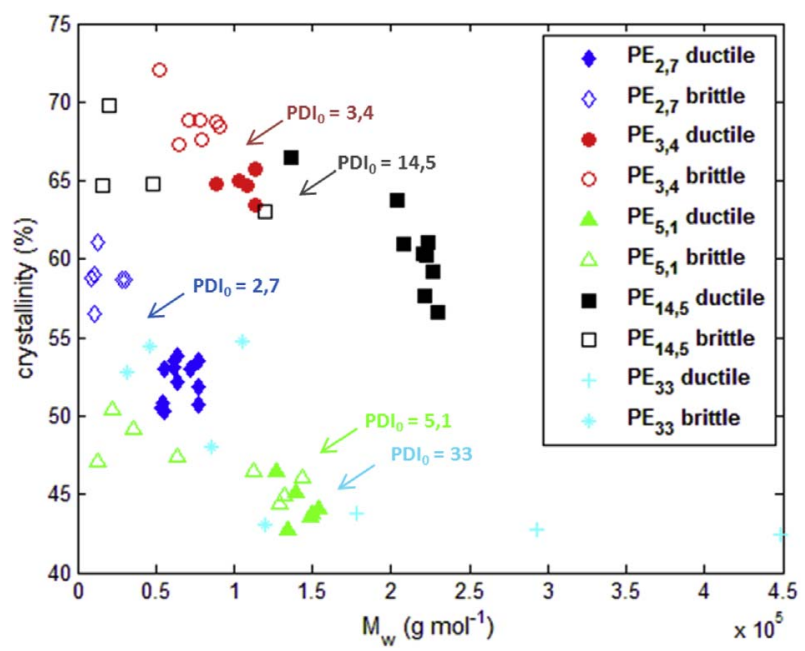

Fig. 10. Percent crystallinity versus molar weight. Open and colored symbols correspond respectively to a "brittle" and ductile behavior; arrows mark the transition between these two behaviors. 


\section{Conclusions}

In this paper, the loss of plastic deformation induced by thermal oxidation of several polyethylenes differing by their initial microstructure, molar mass and polydispersity index was studied. From a macromolecular point of view, chain scissions were always shown to predominate. This phenomenon leads to a decrease of molecular weight and an embrittlement when molar mass turns lower than a critical value (denoted by $\mathrm{M}_{\mathrm{C}}^{\prime}$ ) defining lifetime. This latter was expected to be constant for a given polymer family, i.e. almost "universal" for all PE's. Here, this study performed on a range of samples with narrow or wide molar mass distribution showed that $\mathrm{M}_{\mathrm{C}}$ and the chemicrystallization yield, i.e. that end-of-life criteria, depend on the initial broadness of molar mass distribution. It seems that bimodal (highly polydispersed)
PE are designed to be easily processed and reach high mechanical properties but the high polydispersity makes them sensitive to low concentration chain scissions induced by oxidation (which means that an efficient antioxidant package has to be envisaged). It means also that, despite the "quasi universal behavior" of polyethylene towards oxidation (from a kinetic point of view) [4], the end-of-life criterion is here strongly dependent of the chosen PE grade.

\section{Acknowledgements}

Authors gratefully acknowledge the Carnot ARTS Institute for its financial support to acquire an Agilent Technologies PL-GPC 220 high temperature device (project CEQUAM).

\section{Appendix. Changes of melting temperature with exposure time}

Changes in melting temperature are given in Fig. 11. Melt temperature changes display only very moderate changes (almost $1{ }^{\circ} \mathrm{C}$ which can be considered as falling in the incertitude of the DSC apparatus). We stress on the fact that during ageing, the crystal/amorphous interface energy is expected to change. Assuming that such changes occur mainly at high conversion degrees (in terms of polar products build-up) and that interface energy remains constant in the induction period, the calculated value of $1_{C}$ would increase by about $1 \mathrm{~nm}$ for each PE under investigation. However, having in mind this strong hypothesis, and given the difficulty to perform SAXS analysis on very thin films ( $15 \mu \mathrm{m}$ ), we decided to consider $\mathrm{x}_{\mathrm{C}}$ (from DSC) as the most reliable description of the semi-crystalline morphology (Fig. 10).

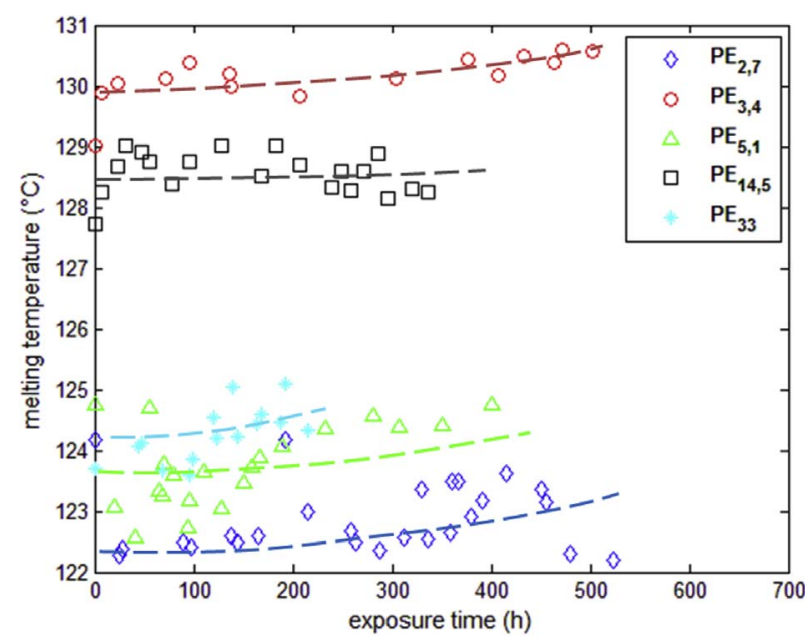

Fig. 11. Melting temperature changes during thermal ageing at $100^{\circ} \mathrm{C}$.

\section{References}

[1] K. Jordens, G.L. Wilkes, J. Janzen, D.C. Rohlfing, M.B. Welch, The influence of molecular weight and thermal history on the thermal, rheological, and mechanical properties of metallocene-catalyzed linear polyethylenes, Polymer 41 (19) (September 2000) 7175-7192.

[2] J. Huang, G.L. Rempel, Ziegler-Natta catalysts for olefin polymerization: mechanistic insights from metallocene systems, Prog. Polym. Sci. 20 (3) (1995) 459-526.

[3] J. Lemaire, R. Arnaud, J.-L. Gardette, Low temperature thermo-oxidation of thermoplastics in the solid state, Polym. Degrad. Stabil. 33 (2) (1991) 277-294.

[4] X. Colin, B. Fayolle, L. Audouin, J. Verdu, About a quasi-universal character of unstabilised polyethylene thermal oxidation kinetics, Polym. Degrad. Stabil. 80 (1) (2003) 67-74.

[5] B. Fayolle, X. Colin, L. Audouin, J. Verdu, Mechanism of degradation induced embrittlement in polyethylene, Polym. Degrad. Stabil. 92 (2) (February 2007) 231-238.

[6] E.M. Hoàng, N.S. Allen, C.M. Liauw, E. Fontán, P. Lafuente, The thermo-oxidative degradation of metallocene polyethylenes. Part 1: long-term thermal oxidation in the solid state, Polym. Degrad. Stabil. 91 (6) (June 2006) 1356-1362.

[7] X. Sun, H. Shen, B. Xie, W. Yang, M. Yang, Fracture behavior of bimodal polyethylene: effect of molecular weight distribution characteristics, Polymer 52 (2) (2011) 564-570.

[8] P.J. DesLauriers, M.P. McDaniel, D.C. Rohlfing, R.K. Krishnaswamy, S.J. Secora, E.A. Benham, P. Maeger, A.R. Wolfe, A.M. Sukhadia, B.B. Beaulieu, A comparative study of multimodal vs. bimodal polyethylene pipe resins for PE-100 applications,
Polym. Eng. Sci. 45 (9) (2005) 1203-1213.

[9] B. Fayolle, E. Richaud, X. Colin, J. Verdu, Degradation-induced embrittlement in semi-crystalline polymers having their amorphous phase in rubbery state, J. Mater. Sci. 43 (22) (2008) 6999-7012.

[10] D.J. Carlsson, G. Bazan, S. Chmela, D.M. Wiles, K.E. Russell, Oxidation of solid polyethylene films: effects of backbone branching, Polym. Degrad. Stabil. 19 (3) (1987) 195-206.

[11] N. Khelidj, X. Colin, L. Audouin, J. Verdu, A simplified approach for the lifetime prediction of PE in nuclear environments, Nucl. Instrum. Methods Phys. Res. Sect. B Beam Interact. Mater. Atoms 236 (Issues 1-4) (July 2005) 88-94.

[12] M.C. Celina, Review of polymer oxidation and its relationship with materials performance and lifetime prediction, Polym. Degrad. Stabil. 98 (12) (December 2013) 2419-2429.

[13] C. Gabriel, E. Kokko, B. Löfgren, J. Seppälä, H. Münstedt, Analytical and rheological characterization of long-chain branched metallocene-catalyzed ethylene homopolymers, Polymer 43 (24) (November 2002) 6383-6390.

[14] A.E. Hamielec, J.B.P. Soares, Polymerization reaction engineering - metallocene catalysts, Prog. Polym. Sci. 21 (4) (1996) 651-706.

[15] F.M. Mirabella, A. Bafna, Determination of the crystallinity of polyethylene/ $\alpha$ olefin copolymers by thermal analysis: relationship of the heat of fusion of $100 \%$ polyethylene crystal and the density, J. Polym. Sci. B Polym. Phys. 40 (15) (August 2002) 1637-1643.

[16] B. Fayolle, L. Audouin, J. Verdu, A critical molar mass separating the ductile and brittle regimes as revealed by thermal oxidation in polypropylene, Polymer 45 (12) (May 2004) 4323-4330.

[17] E. Richaud, X. Colin, B. Fayolle, L. Audouin, J. Verdu, Induction period in the low- 
temperature thermal oxidation of saturated hydrocarbons: example of polyethylene, Int. J. Chem. Kinet. 40 (12) (December 2008) 769-777.

[18] C. Devilliers, B. Fayolle, L. Laiarinandrasana, S. Oberti, E. Gaudichet-Maurin, Kinetics of chlorine-induced polyethylene degradation in water pipes, Polym. Degrad. Stabil. 96 (7) (2011) 1361-1368.

[19] O. Saito, On the effect of high energy radiation to polymers: I. Cross-linking and degradation, J. Phys. Soc. Jpn. 13 (2) (1958) 198-206.

[20] A. Smedberg, T. Hjertberg, B. Gustafsson, Crosslinking reactions in an unsaturated low density polyethylene, Polymer 38 (16) (1997) 4127-4138.

[21] S. Wu J, Chain structure and entanglement, Pol. Sci. Part B: Polym Phys 27 (March
1989) 723-741.

[22] M.S. Rabello, J.R. White, Crystallization and melting behaviour of photodegraded polypropylene - I. Chemi-crystallization, Polymer 38 (26) (1997) 6379-6387.

[23] J. Viebke, E. Elble, M. Ifwarson, U.W. Gedde, Degradation of unstabilized mediumdensity polyethylene pipes in hot-water applications, Polym. Eng. Sci. 34 (17) (September 1994) 1354-1361.

[24] O. Okamba-Diogo, E. Richaud, J. Verdu, F. Fernagut, J. Guilment, B. Fayolle, Investigation of polyamide 11 embrittlement during oxidative degradation, Polymer 82 (15) (January 2016) 49-56. 